\title{
AN ANALYSIS OF BICARBONATE REABSORPTION DURING PARTIAL INHIBITION OF CARBONIC ANHYDRASE ${ }^{1}$
}

\author{
By WILLIAM B. SCHWARTZ,2 ADRIEN FALBRIARD, 3 AND \\ ARNOLD S. RELMAN \\ (From the Department of Medicine, Tufts University School of Medicine, and Boston Uni- \\ versity School of Medicine, and from the Medical Service of the New England \\ Center Hospital and the Evans Memorial, Massachusetts Memorial \\ Hospitals, Boston, Mass.)
}

(Submitted for publication August 1, 1957; accepted January 10, 1958)

A considerable body of evidence supports the view that the bicarbonate diuresis produced by acetazolamide (Diamox ${ }^{\circledR}$ ) results from inhibition of carbonic anhydrase activity in renal tubular cells (1-3). In a preliminary study (4), it was found that this diuresis was reduced if metabolic acidosis was induced prior to the administration of the drug. This phenomenon has subsequently been observed repeatedly in clinical and experimental studies (5-8). It is now well known that patients with metabolic acidosis do not respond to acetazolamide and that the acidosis resulting from the administration of acetazolamide is an important factor in the development of resistance to continued treatment with this drug (9-11).

Some workers have found an apparent threshold for acetazolamide activity at plasma bicarbonate levels of approximately $16 \mathrm{mEq}$. per L. (6). At levels below this threshold, oral administration of acetazolamide is said to have no effect. Other studies have reported marked reduction of acetazolamide action in metabolic acidosis but no absolute threshold (5).

The explanations given for the reduction in response during metabolic acidosis are that $a$ ) a certain portion of the bicarbonate reabsorptive process in the renal tubule is normally not dependent on carbonic anhydrase activity, or that $b$ ) the importance of the enzyme in the reabsorptive process is in some way reduced by metabolic acidosis.

\footnotetext{
1 Supported in part by grants from the National Heart Institute, National Institutes of Health, United States Public Health Service, and the American Heart Association.

2 This work was done during the tenure of an Established Investigatorship of the American Heart Association.

3 This work was done during the tenure of a Lederle Travelling Fellowship.
}

In the present experiments the action of acetazolamide in dogs was studied at several dose levels and during varying degrees of metabolic acidosis. With each of the doses separate but similar curves were obtained demonstrating a diminishing effect of the drug on the reabsorptive process as plasma bicarbonate concentration was reduced. The two larger doses of acetazolamide reduced reabsorptive rates significantly even at the lowest plasma levels studied, thus suggesting that carbonic anhydrase activity is involved in the reabsorption of most, if not all, of the filtered bicarbonate. An attempt has been made to explain these findings in the light of classical Michaelis-Menten enzyme kinetics.

\section{MATERIAL AND METHODS}

Sixty-three experiments were performed on $47 \mathrm{fe}-$ male mongrel dogs weighing from 9 to $15 \mathrm{Kg}$. Light general anesthesia was obtained by intravenous administration of morphine or sodium pentobarbital. Metabolic acidosis and the desired plasma levels of bicarbonate ( 5 to $22 \mathrm{mEq}$. per L.) were achieved by infusion of appropriate amounts of $\mathrm{HCl}$ or by oral administration of $\mathrm{NH}_{4} \mathrm{Cl}$. This was followed by continuous infusion of isotonic $\mathrm{NaCl}$ at a steady rate of 6.5 to $10 \mathrm{ml}$. per minute through a Bowman infusion pump.

Urine was collected under neutral mineral oil through an inlying bladder catheter and the bladder was emptied by manual compression at the end of each collection period.

The clearance of exogenous creatinine was used as a measure of glomerular filtration rate. Plasma and urine were analyzed for creatinine by a modification of the method of Bonsnes and Taussky (12) and for total $\mathrm{CO}_{2}$ content by the manometric method of Van Slyke. Blood and urine $\mathrm{pH}$ were determined anaerobically at room temperature in a syringe-type Cambridge $\mathrm{pH}$ meter and corrected to $37^{\circ} \mathrm{C}$. (using a correction factor of 0.01 units per degree C.). Carbon dioxide tension in urine and blood was calculated from the Henderson-Hasselbalch equation, using a value of 6.1 for the $\mathrm{pK}_{1}$ and a value for $\alpha$ in blood of 0.0301 and in urine of 0.0309 . Bicarbonate concentration was calculated as the difference be- 
TABLE I

Comparative effects of $1 \mathrm{mg}$., $5 \mathrm{mg}$., and $20 \mathrm{mg}$. per $\mathrm{Kg}$. of acetazolamide on bicarbonate excretion and reabsorption at similar plasma bicarbonate concentrations *

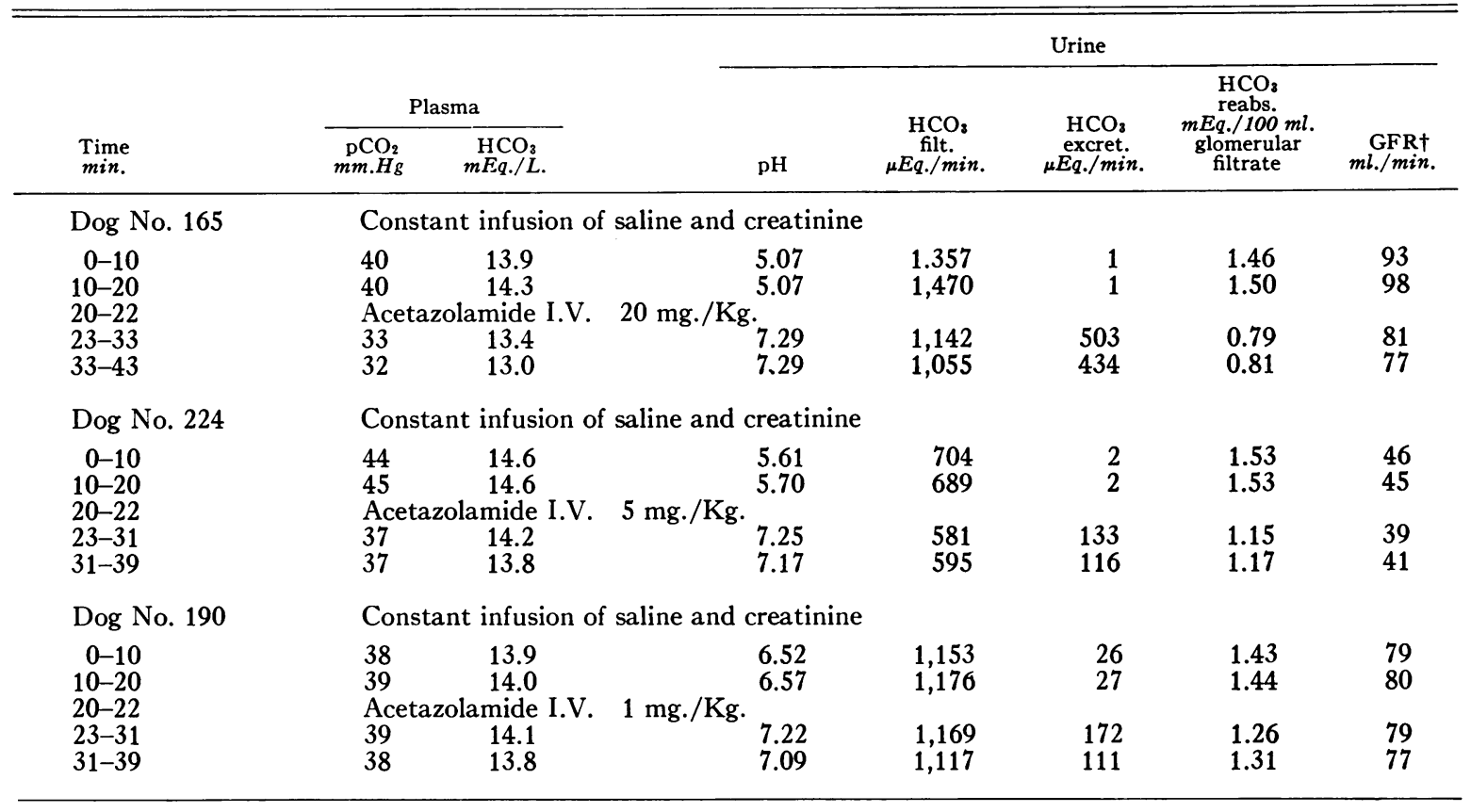

* A Donnan factor of 1.05 was used in calculating filtered load.

$\dagger$ Glomerular filtration rate.

TABLE II

Effects of $20 \mathrm{mg}$. and $5 \mathrm{mg}$. per $\mathrm{Kg}$. of acetazolamide on bicarbonate excretion and reabsorption at low plasma bicarbonate concentrations *

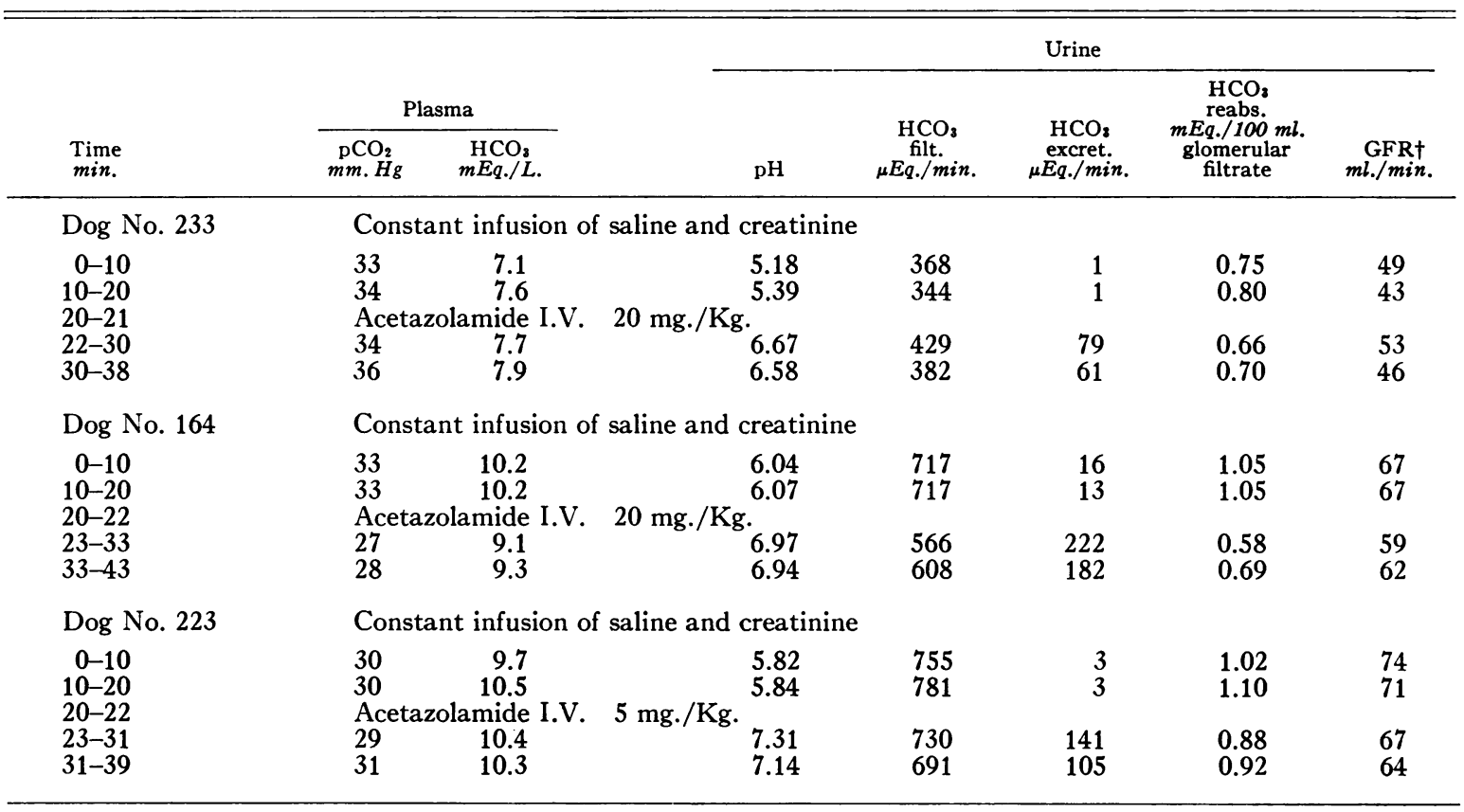

* A Donnan factor of 1.05 was used in calculating filtered load. $\dagger$ Glomerular filtration rate. 
tween the total $\mathrm{CO}_{2}$ content and the dissolved carbon dioxide. Filtered bicarbonate was taken as the product of the filtration rate and the plasma bicarbonate concentration, corrected for a Donnan factor of 1.05 .

Following at least two control periods of 8 to $10 \mathrm{~min}$ utes each, the acetazolamide was injected intravenously over a period of one to two minutes. One minute after the end of the injection, two or three more urine periods of 6 to 10 minutes each were obtained. Three dosages of acetazolamide were used: one $\mathrm{mg}$. per $\mathrm{Kg}$. of body weight, $5 \mathrm{mg}$. per $\mathrm{Kg}$., and 20 to $40 \mathrm{mg}$. per $\mathrm{Kg}$. Since no difference of action was observed between $20 \mathrm{mg}$. per $\mathrm{Kg}$. and $40 \mathrm{mg}$. per $\mathrm{Kg}$., this dosage range was assumed to achieve virtually the same degree of carbonic anhydrase inhibition. The acetazolamide solution was prepared by adding the powder to approximately $20 \mathrm{ml}$. of distilled water containing approximately 0.7 to $0.8 \mathrm{mEq}$. of alkali per $100 \mathrm{mg}$. of drug.

\section{RESULTS}

In every experiment with doses of 5 or 20 to $40 \mathrm{mg}$. per $\mathrm{Kg}$., acetazolamide produced a definite increase in bicarbonate excretion. The magnitude of this effect diminished with increasing metabolic acidosis, but remained significant even at the lowest plasma bicarbonate levels. On the other hand,

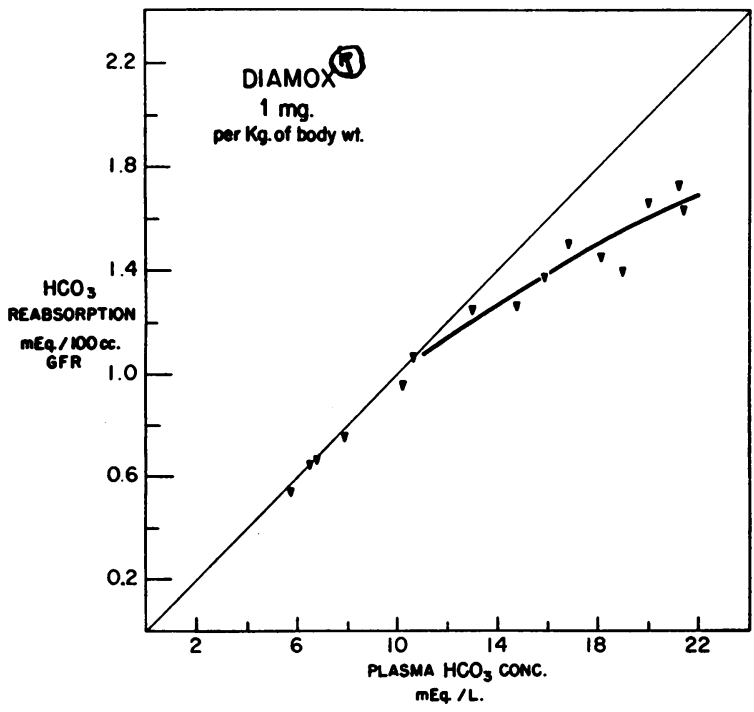

Fig. 1. Relationship Between Bicarbonate Reabsorption and Plasma Bicarbonate Concentration Following Administration of Intravenous AcetazolAMIDE 1 MG. PER KG.

Each point represents one experiment. The heavy line was drawn through the experimental points by inspection. The thin line bisecting the graph represents the control reabsorption. In this and all subsequent figures the plasma levels have been corrected by a Donnan factor of 1.05 .

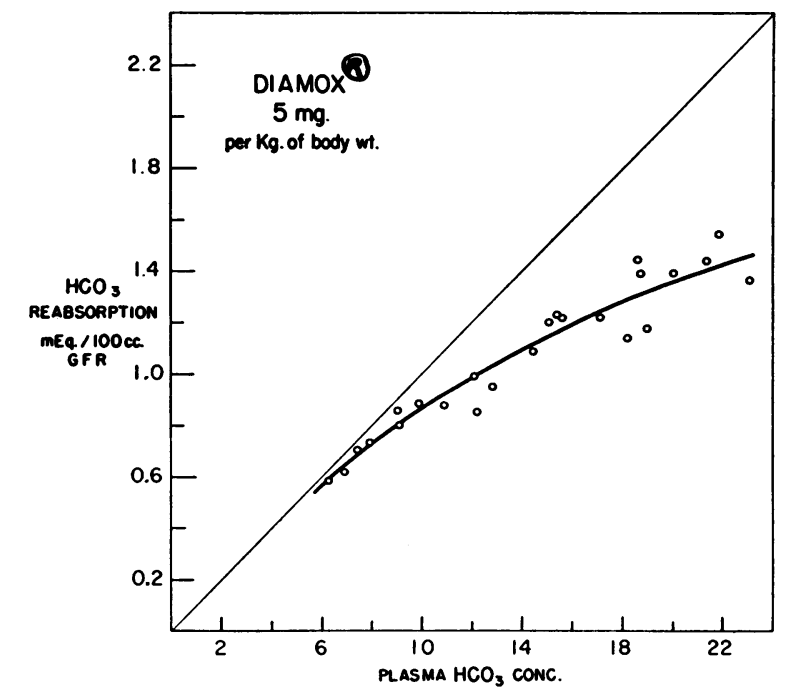

mEq. $/ L$.

Fig. 2. Retationship Between Bicarbonate Reabsorption and Plasma Bicarbonate Concentration Following Administration of Intravenous AcetazolAMIDE 5 MG. PER KG.

See Figure 1 for details.

at any given plasma concentration, the higher the dosage of the drug the greater was the response. With $1 \mathrm{mg}$. per $\mathrm{Kg}$. a significant effect on bicarbonate excretion was observed at the higher plasma bicarbonate levels, but below $12 \mathrm{mEq}$. per L. the effects were negligible. Table I compares the effect of $20 \mathrm{mg}$., $5 \mathrm{mg}$., and $1 \mathrm{mg}$. per $\mathrm{Kg}$. of acetazolamide on bicarbonate excretion and reabsorption at a plasma bicarbonate level of approximately $14 \mathrm{mEq}$. per L. It is apparent that the effect on bicarbonate reabsorption increased with the dose. That an effect could be clearly demonstrated even at low plasma levels is illustrated by Table II, which summarizes the results of three experiments at plasma bicarbonate levels of 8 to $10 \mathrm{mEq}$. per L. In the first two experiments, a dose of $20 \mathrm{mg}$. per $\mathrm{Kg}$. was used; in the other experiment, the dose was $5 \mathrm{mg}$. per $\mathrm{Kg}$. It is clear that the administration of the drug was followed in each instance by a definite effect on both excretion and reabsorption.

The relationship between the plasma bicarbonate level and the action of different doses of acetazolamide on bicarbonate reabsorption is summarized by Figures 1 to 3 , which include all the experiments. On the abscissa of each graph is plotted plasma bicarbonate concentration and on 
the ordinate is the minimum bicarbonate reabsorption following acetazolamide injection, expressed as milliequivalents of bicarbonate per 100 milliliters of glomerular filtrate. ${ }^{4}$ This minimum reabsorption usually occurred in the first collection period following the injection. The curves have been drawn through the points by inspection. The thin straight line bisecting each plot indicates reabsorption during the control period, when there is essentially complete removal of the filtered bicarbonate. Thus the vertical distance between this line and each experimental point represents the magnitude of acetazolamide effect at each plasma level.

The first fact apparent from these curves is that acetazolamide action diminishes as the plasma bicarbonate level is reduced.

A second fact is that the different dosages of acetazolamide produce different curves of similar

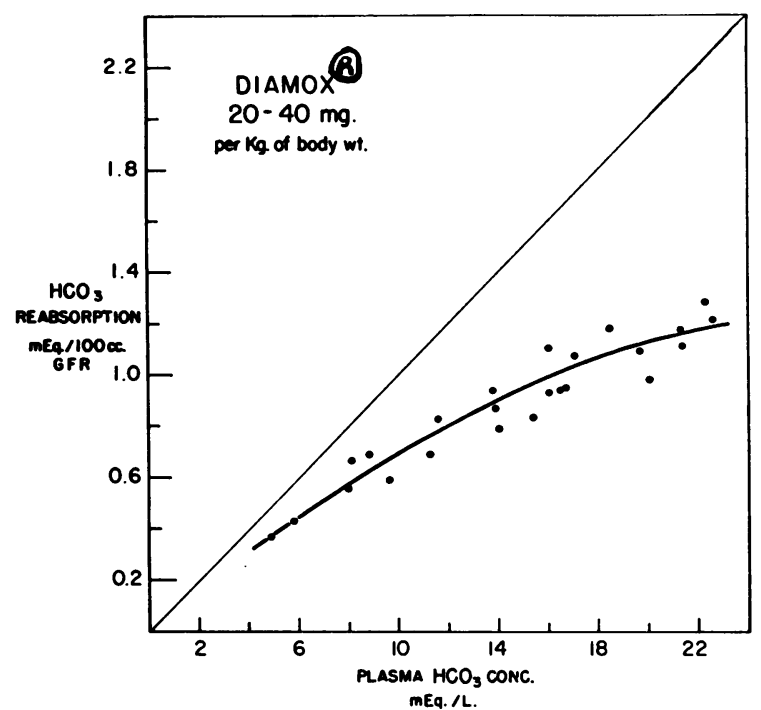

Fig. 3. Relationship Between Bicarbonate ReabSORPtion and Plasma Bicarbonate Concentration Following Administration of Intravenous ACEtazolAMIDE 20 TO 40 Mg. PER KG.

See Figure 1 for details.

4 Correction of the reabsorption rates to a standard glomerular filtration rate is assumed to correct for differences in renal mass between different animals. In individual animals the changes in glomerular filtration rate following the injection of acetazolamide were usually negligible. The mean per cent change from the average control rate, without regard to sign, was 7.9 $\pm 5.5,8.0 \pm$ 6.1 , and $8.5 \pm 8.0$ for the 1,5 , and 20 to $40 \mathrm{mg}$. experiments, respectively.

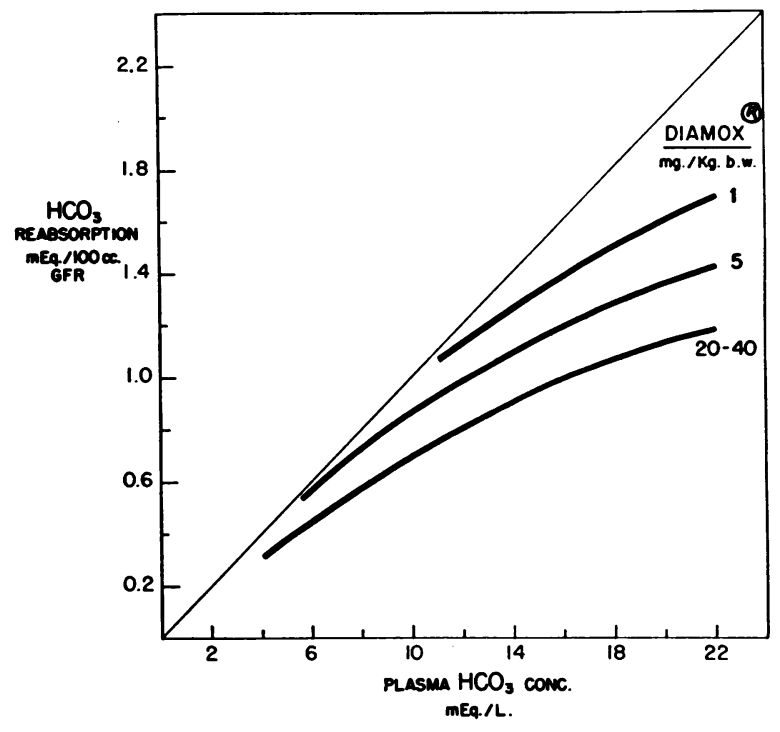

Fig. 4. Relationship Between Bicarbonate Reabsorption and Plasma Bicarbonate Concentration with Three Different Doses of Acetazolamide

The heavy lines from Figures 1 to 3 are plotted together on this graph.

shape. This is illustrated by Figure 4 which compares the action of $1 \mathrm{mg}$., $5 \mathrm{mg}$., and 20 to 40 $\mathrm{mg}$. of acetazolamide per $\mathrm{Kg}$. of body weight on bicarbonate reabsorption.

It can also be seen that at plasma bicarbonate levels below $12 \mathrm{mEq}$. per L., $1 \mathrm{mg}$. per $\mathrm{Kg}$. seems to have no significant effect on reabsorption.

Plasma $\mathrm{pCO}_{2}$ was generally lower during severe acidosis, but respiratory compensation was negligible except with very severe acidosis, probably because of the anesthesia. Figure 5 shows the scatter of the plasma $\mathrm{pCO}_{2}$ values in relation to plasma bicarbonate levels. There is a slight tendency for the $\mathrm{pCO}_{2}$ values to fall with increasing acidosis, but this trend produces appreciable reductions in $\mathrm{pCO}_{2}$ only at plasma bicarbonate levels below $12 \mathrm{mEq}$. per L. At each plasma bicarbonate level there is a wide and apparently random scatter of $\mathrm{pCO}_{2}$ values with respect to acetazolamide dosage. No significant changes in plasma $\mathrm{pCO}_{2}$ were produced by administration of acetazolamide.

\section{DISCUSSION}

The data summarized in Figure 4 show that with three different doses of acetazolamide and over a wide range of plasma bicarbonate concen- 


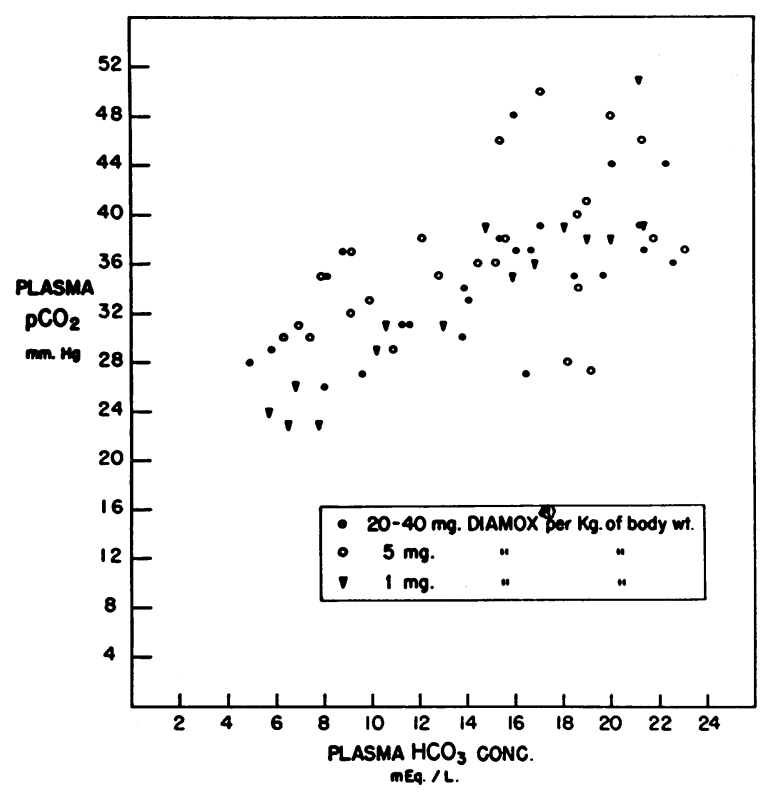

Fig. 5. Relationship Between Plasma $\mathrm{CO}_{2}$ TenSION ANd Bicarbonate Concentration for all ExPERIMENTS

Each point represents one experiment.

tration there is a progressively greater inhibitory effect on bicarbonate reabsorption. With doses of 5 and 20 to $40 \mathrm{mg}$. per $\mathrm{Kg}$. acetazolamide significantly affects bicarbonate reabsorption even at plasma bicarbonate levels as low as 5 to $10 \mathrm{mEq}$. per $\mathrm{L}$. The effect of $1 \mathrm{mg}$. per $\mathrm{Kg}$. becomes negligible at a bicarbonate concentration of about $12 \mathrm{mEq}$. per L. If the only action of acetazolamide, at the doses used, is to partially inhibit carbonic anhydrase activity, it would seem to follow from these observations that carbonic anhydrase is normally involved in the reabsorptive mechanism for most of the filtered bicarbonate. Stated differently, it would appear that there can be only a small fraction of the filtered bicarbonate which is reabsorbed without the participation of the enzyme. If the above considerations are valid then the reabsorptive rates shown in Figures 1 to 4 would seem to be a function of residual enzyme activity after partial inhibition by acetazolamide.

No obvious explanation of the relationship between plasma bicarbonate concentration and bicarbonate reabsorption is at hand, but a tentative hypothesis may be offered. Assuming that the reabsorption of bicarbonate after administration of acetazolamide is dependent on enzyme activity, then the fact that three different curves are obtained with three different doses of inhibitor would suggest that in each instance the enzymatic reaction is the rate-limiting step in the overall process leading to bicarbonate reabsorption. If this were so, classical Michaelis-Menten enzyme kinetics might provide an approximate overall description of the reabsorptive process. To test the applicability of the Michaelis-Menten analysis in this situation, however, it is necessary to make several assumptions which would permit the use of the available data as terms in the kinetic equation. It is recognized that the validity of these assumptions may be questioned, but it is considered of interest to determine whether a unifying theory might be derived which could provide an adequate explanation for the data. For this purpose the following assumptions were made:

1. The bicarbonate in the tubular fluid is considered to be in effect the substrate for the enzyme. This could be true even if the actual substrate were some other intermediate compound formed in a series of rapid reactions leading to the removal of bicarbonate from the filtrate, because the concentration of this substrate could be some direct linear function of the bicarbonate concentration in the tubular fluid.

2. Because of the constant supply of substrate from the filtrate and the constant rapid removal of the reaction products, it is assumed that at any given point along the tubule there is no change in the concentration of the enzyme-substrate complex from moment to moment. The concentration of this complex determines the reaction velocity, and it would therefore follow that the observed reabsorption rates represent a steady-state condition.

3. In this application of the Michaelis-Menten analysis to the tubule as a whole, it has been assumed, finally, that the filtrate bicarbonate concentration is equal to, or is some direct and constant function of, the mean tubular bicarbonate concentration for the overall reabsorptive process. ${ }^{5}$

\footnotetext{
5 One mechanism which might nearly satisfy the conditions of this assumption is suggested by micropuncture studies in Necturus. These indicate that the bicarbonate concentration remains constant throughout the proximal tubule (13). In the dog, this would mean that at least 80 per cent of the reabsorptive process occurs at a constant concentration. Obviously, if the urine is alkalinized
} 
In the replotting of the experimental data, the Lineweaver-Burk modification of the MichaelisMenten equation was used :

$\begin{array}{ll}\text { 1) } \mathrm{v}=\frac{\mathrm{V}_{\max } \mathrm{s}}{\mathrm{K}_{\mathrm{m}}+\mathrm{s}} & \text { (Michaelis-Menten) } \\ \text { 2) } \frac{1}{\mathrm{v}}=\frac{1}{\mathrm{~V}_{\max }}+\frac{\mathrm{K}_{\mathrm{m}}}{\mathrm{V}_{\max }}(1 / \mathrm{s}) & \text { (Lineweaver-Burk), }\end{array}$ where

$\mathbf{v}=$ The steady-state velocity of the reaction (bicarbonate reabsorption per 100 ml. glomerular filtrate)

$\mathbf{s}=$ The substrate concentration (bicarbonate concentration per $100 \mathrm{ml}$. of filtrate)

$\mathrm{V}_{\max }=$ The maximum velocity of the reaction (a constant for any given amount of enzyme)

$K_{m}=$ The Michaelis constant for the enzyme, which has the dimension of a concentration.

Figure 6 shows the experimental data replotted according to equation 2) with $1 / \mathrm{v}$ as the ordinate and $1 / \mathrm{s}$ as the abscissa. In this figure the six lowest points with $1 \mathrm{mg}$. per $\mathrm{Kg}$. are omitted, since (Figure 1) they do not differ significantly from the straight line representing complete reabsorption, and since Michaelis-Menten kinetics only apply to situations in which enzyme is rate-limiting. With only $1 \mathrm{mg}$. per $\mathrm{Kg}$. of inhibitor there apparently is enough residual enzyme activity to make the substrate the limiting factor when bicarbonate concentration drops below 10 to $12 \mathrm{mEq}$. per $\mathrm{L}$.

The regression equations for the three lines indicated on the figure were calculated by the method of least squares. For $1 \mathrm{mg}$. per $\mathrm{Kg}$. the equation is : $y=0.26+0.74 x(r=0.91)$; for $5 \mathrm{mg}$. per $\mathrm{Kg}$. it is: $\mathrm{y}=0.32+0.85 \mathrm{x}(\mathrm{r}=0.98)$; and for 20 to $40 \mathrm{mg}$. per Kg., $\mathrm{y}=0.33+1.14 \mathrm{x}(\mathrm{r}=$ $0.98)$. It is apparent that each set of experimental points closely fits the straight line predicted by equation 2). The slope of the lines increases with the dose of inhibitor used. This type of plot, with

or acidified in the distal fifth of the tubule, this would result in some discrepancy between the filtrate concentration and the actual mean. For the purpose of this analysis, it is assumed that any such discrepancy would not be critical.

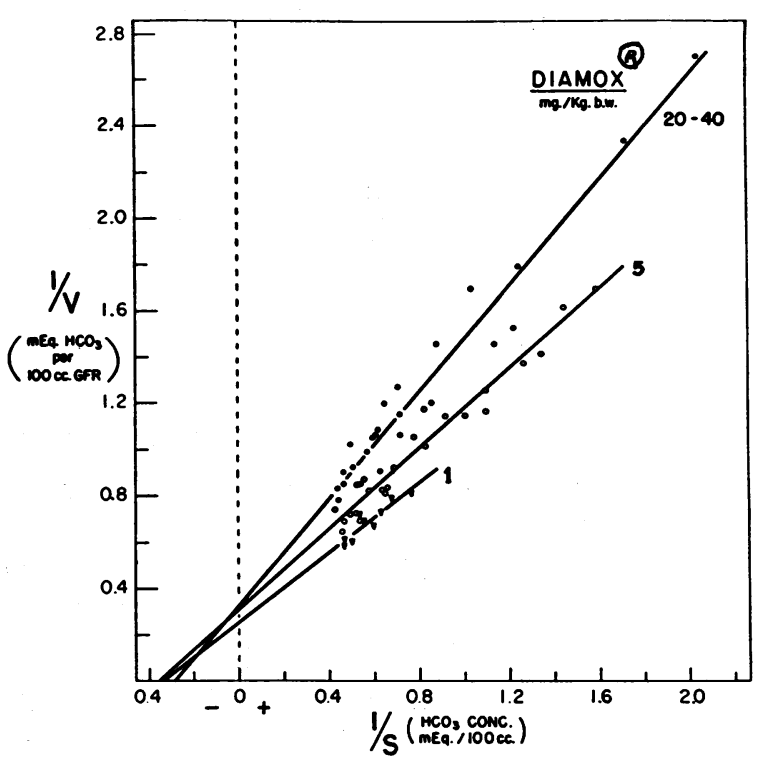

Fig. 6. Relationship Between the Reciprocal of the Bicarbonate Reabsorption Rate and the Reciprocal of the Plasma Bicarbonate Concentration (Lineweaver-Burk Modification of the MichaelisMenten Equation)

The lines through each of the three sets of data were calculated by the method of least squares.

increasing doses of acetazolamide yielding distinct straight lines of increasing slope, is characteristic of the effect of an enzyme inhibitor on the rate of an enzyme-limited process.

Intersection of the lines on the abscissa is characteristic of noncompetitive inhibition, while intersection on the ordinate is typical of competitive inhibition. In Figure 6 it is apparent that the three intercepts on both axes are so close together that it is impossible to distinguish between these two types of inhibition. Recent in vitro studies indicate that sulfanilamide is a noncompetitive inhibitor of carbonic anhydrase (14), but the present data do not permit any firm conclusion about the exact type of inhibition produced by acetazolamide in vivo.

Different values of $\mathrm{V}_{\max }$ for the uninhibited system can be calculated from the present data, depending upon the type of inhibition assumed. The calculation is made below for both types:

In noncompetitive inhibition, $\mathrm{K}_{\mathrm{m}}$ is unaffected by the presence of the inhibitor, but $\mathrm{V}_{\max }$ is decreased by a factor which is proportional to the concentration of the inhibitor. The Lineweaver- 
Burk equation for this type of inhibition is:

3) $\frac{1}{\mathrm{v}}=\left(1+\frac{\mathrm{I}}{\mathrm{K}_{\mathrm{i}}}\right)\left(\frac{1}{\mathrm{~V}_{\max }}+\frac{\mathrm{K}_{\mathrm{m}}}{\mathrm{V}_{\max }} \cdot \frac{1}{\mathrm{~s}}\right)$,

where $\mathrm{I}=$ Concentration of inhibitor, $\mathrm{K}_{1}=$ Dissociation constant for the enzyme-inhibitor complex.

In equation 3 , the intercept on the $1 / \mathrm{s}$ axis is $-1 / K_{m}$. Estimated from Figure $6, K_{m}$ has a value of approximately $2.9 \mathrm{mEq}$. per $100 \mathrm{ml}$.

From this value of $\mathrm{K}_{\mathrm{m}}$ it is possible to obtain a minimum estimate of the in vivo $\mathrm{V}_{\max }$ for the uninhibited enzyme, since $K_{m}$ is the concentration of substrate at which $\mathrm{v}$ equals $\mathrm{V}_{\max } / 2$. At $29 \mathrm{mEq}$. per L., or for that matter at all plasma levels above $25 \mathrm{mEq}$. per L., the normal reabsorptive rate is approximately $2.5 \mathrm{mEq}$. per minute per $100 \mathrm{ml}$. glomerular filtrate (1). It follows that the value of $\mathrm{V}_{\max }$ for the uninhibted enzyme in vivo would be at least $5.0 \mathrm{mEq}$. per $100 \mathrm{ml}$. glomerular filtrate.

On the other hand, if Figure 6 is interpreted as indicating competitive inhibition, $\mathrm{V}_{\max }$ can be calculated from the Lineweaver-Burk equation for this type of inhibition:

4) $\frac{1}{v}=\frac{1}{V_{\max }}\left(K_{m}+\frac{K_{m}(I)}{K_{i}}\right) \frac{1}{(s)}+\frac{1}{V_{\max }}$.

Estimated as the reciprocal of the intercept on the $y$ axis, the mean value of $V_{\max }$ calculated from the regression equations of Figure 6 would thus be $3.4 \mathrm{mEq}$. per $100 \mathrm{ml}$. glomerular filtrate.

Assuming either type of inhibition, the data thus suggest that the normal maximal rate of bicarbonate reabsorption of approximately 2.5 $\mathrm{mEq}$. per $100 \mathrm{ml}$. glomerular filtrate is less than the maximal rate at which the carbonic anhydrase reaction could proceed. It is, therefore, tentatively proposed that the kinetic limitations of this enzyme are not responsible for the establishment of the normal bicarbonate threshold.

The data are consistent with the hypothesis that at plasma bicarbonate levels below the usual threshold, partial inhibition of carbonic anhydrase makes enzyme activity the rate-limiting step in the process of bicarbonate reabsorption. Under these conditions the overall process of reabsorption appears to follow the Michaelis-Menten relationship in a consistent fashion. It is evident that normally, in the absence of an inhibitor, the reabsorptive process is virtually complete at all plasma levels below $25 \mathrm{mEq}$. per $\mathrm{L}$. In other words, substrate presentation (filtered bicarbonate) and the velocity of the reaction (bicarbonate reabsorption) bear a linear relationship to each other at subthreshold levels. This would suggest that in the absence of an inhibitor the enzymatic reaction is not the rate-limiting step. Some other process, in all likelihood the filtration of bicarbonate, probably limits the rate of presentation of substrate to the enzyme.

While the behavior of the system under study apparently can be described in terms of enzyme kinetics, it is obvious that many other factors might influence it. Changes in cellular potassium content as well as marked alterations in $\mathrm{pCO}_{2}$ are known to affect bicarbonate reabsorption. The mechanisms through which these influences operate are not clarified by this study, but the present observations may provide a reasonable framework for further investigations of these problems.

\section{SUMMARY}

The effects on renal bicarbonate reabsorption of 1,5 , and 20 to $40 \mathrm{mg}$. per $\mathrm{Kg}$. of acetazolamide have been studied in acidotic dogs whose plasma bicarbonate concentrations ranged from 5 to 22 $\mathrm{mEq}$. per L. With each of the doses separate but similar curves were obtained demonstrating a diminishing effect of the drug on the reabsorptive process as plasma bicarbonate concentration was reduced. The two larger doses of acetazolamide reduced reabsorptive rates significantly even at the lowest plasma levels studied, thus suggesting that carbonic anhydrase activity is involved in the reabsorption of most, if not all, of the filtered bicarbonate. An attempt has been made to explain these findings in the light of classical MichaelisMenten enzyme kinetics.

\section{ACKNOWLEDGMENTS}

The authors gratefully acknowledge their indebtedness to Dr. Robert Davis for his helpful advice and guidance in the theoretical analysis of the data. We are also very grateful to Dr. Peter A. W. Bernfeld for his valuable advice.

\section{REFERENCES}

1. Pitts, R. F., and Lotspeich, W. D. Bicarbonate and the renal regulation of acid base balance. Amer. J. Physiol. 1946, 147, 138. 
2. Berliner, R. W., Kennedy, T. J., Jr., and Orloff, J. Relationship between acidification of the urine and potassium metabolism. Amer. J. Med. 1951, 11, 274.

3. Berliner, R. W., and Orloff, J. Carbonic anhydrase inhibitors. Pharmacol. Rev. 1956, 8, 137.

4. Schwartz, W. B., Danzig, L. E., and Relman, A. S. Role of carbonic anhydrase in renal tubular reabsorption of bicarbonate (abstract). Amer. J. Med. 1953, 14, 526.

5. Maren, T. H., Wadsworth, B. C., Yale, E. K., and Alonso, L. G. Carbonic anhydrase inhibition. III. Effects of Diamox ${ }^{(B)}$ on electrolyte metabolism. Bull. Johns Hopk. Hosp. 1954, 95, 277.

6. Counihan, T. B., Evans, B. M., and Milne, M. D. Observations on the pharmacology of the carbonic anhydrase inhibitor "Diamox." Clin. Sci. 1954, 13, 583.

7. Maren, T. H. Carbonic anhydrase inhibition. IV. The effects of metabolic acidosis on the response to Diamox B. Bull. Johns Hopk. Hosp. 1956, 98, 159.

8. Hanley, T., and Platts, M. M. Diminishing effect of carbonic anhydrase inhibitor acetazoleamide on urinary bicarbonate excretion. J. appl. Physiol. 1956, 9, 279.

9. Leaf, A., Schwartz, W. B., and Relman, A. S. Oral administration of a potent carbonic anhydrase inhibitor ("Diamox"). I. Changes in electrolyte and acid-base balance. New Engl. J. Med. 1954, 250, 759.

10. Relman, A. S., Leaf, A., and Schwartz, W. B. Oral administration of a potent carbonic anhydrase inhibitor ("Diamox"). II. Its use as a diuretic in patients with severe congestive heart failure. New Engl. J. Med. 1954, 250, 800.

11. Falbriard, A. Action rénale des sulfamides inhibiteurs de la carboanhydrase. Intérêt physiologique et applications cliniques. Praxis 1954, 43, 265 and 293.

12. Bonsnes, R. W., and Taussky, H. H. On the colorimetric determination of creatinine by the Jaffe reaction. J. biol. Chem. 1945, 158, 581.

13. Giebisch, G. Measurements of $\mathrm{pH}$, chloride and inulin concentrations in proximal tubule fluid of Necturus. Amer. J. Physiol. 1956, 185, 171.

14. Davis, R. P. Personal communication. 